\title{
1 A triad of kicknet sampling, eDNA metabarcoding, 2 and predictive modeling to assess aquatic 3 macroinvertebrate biodiversity
}

5 François Keck ${ }^{1, *}$, Samuel Hürlemann ${ }^{1}$, Nadine Locher $^{1}$, Christian Stamm ${ }^{2}$, Kristy Deiner ${ }^{1,3, \$}$ 6 and Florian Altermatt ${ }^{1,4, \$}$

8 'Eawag: Swiss Federal Institute of Aquatic Science and Technology, Department of Aquatic 9 Ecology, Überlandstr. 133, CH-8600 Dübendorf, Switzerland.

10 2Eawag: Swiss Federal Institute of Aquatic Science and Technology, Department of 11 Environmental Chemistry, Überlandstr. 133, CH-8600 Dübendorf, Switzerland.

$12{ }^{3}$ ETH, Department of Environmental Systems Science, Universitätstr. 16, CH-8092 Zürich, 13 Switzerland

$14{ }^{4}$ Department of Evolutionary Biology and Environmental Studies, University of Zurich, 15 Winterthurerstr. 190, CH-8057 Zürich, Switzerland.

corresponding authors: Francois.Keck@eawag.ch and Florian.Altermatt@eawag.ch

18 \$ shared last co-authorship

20 Running title : A triad of methods to assess aquatic macroinvertebrate biodiversity 


\section{Abstract}

Monitoring freshwater biodiversity is essential to understand the impacts of human activities and for effective management of ecosystems. Thereby, biodiversity can be assessed through direct collection of targeted organisms, through indirect evidence of their presence (e.g. signs, environmental DNA, camera trap, etc.), or through extrapolations from species distribution models (SDM). Differences in approaches used in biodiversity assessment, however, may come with individual challenges and hinder cross-study comparability. In the context of rapidly developing techniques, we compared a triad of approaches in order to understand assessment of aquatic macroinvertebrate biodiversity. Specifically, we compared the community composition and species richness of three orders of aquatic macroinvertebrates (mayflies, stoneflies, and caddisflies, hereafter EPT) obtained via eDNA metabarcoding and via traditional in situ kicknet sampling to catchment-level based predictions of a species distribution model. We used kicknet data from 24 sites in Switzerland and compared taxonomic lists to those obtained using eDNA amplified with two different primer sets. Richness detected by these methods was compared to the independent predictions made by a statistical species distribution model using landscapelevel features to estimate EPT diversity. Despite the ability of eDNA to consistently detect some EPT species found by traditional sampling, we found important discrepancies in community composition between the two approaches, particularly at local scale. Overall, the more specific set of primers, namely fwhF2/EPTDr2n, was most efficient for the detection of target species and for characterizing the diversity of EPT. Moreover, we found that the species richness measured by eDNA was poorly correlated to the richness measured by kicknet sampling and that the richness estimated by eDNA and kicknet were poorly correlated with the prediction of the statistical model. Overall, however, neither eDNA nor the traditional approach had strong links to the predictive models, indicating inherent limitations in upscaling species richness estimates. Future challenges include improving the accuracy and sensitivity of each approach individually yet also acknowledge their respective limitations, in order to best meet stakeholder demands addressing the biodiversity crisis we are facing.

\section{Keywords}

Metabarcoding, water DNA, Ephemeroptera, Plecoptera, Trichoptera

\section{Introduction}

The role of biodiversity in maintaining ecosystem functions and services is widely recognized (Chapin 2000, Cardinale 2012). Consequently, deleterious effects of human activities on biodiversity are a source of growing concern and are mobilising both scientists and stakeholders around the world (Pereira \& Cooper 2006, Diaz et al. 2020). In a context where the loss of biodiversity is established and threatens many of the benefits that ecosystems provide to humanity, monitoring the diversity and composition of biological communities is a priority, both to prevent future adverse consequences and to establish possible restoration measures (Lindenmayer \& Likens 2010). However, measuring state and change of biodiversity remains a challenge both due to questions related to its scientific definition (such as which levels of biological organisation to study and at what spatial scales) and to the limitation of the methods and technologies available to monitor life in the environment.

For a long time, freshwater biodiversity monitoring has solely relied on the capture of individuals or their direct observation. These approaches, although improved over time, remain limited by sampling biases, identification errors, associated costs, and sometimes coarse taxonomic resolution. Furthermore, they do not allow upscaling and predicting to 
68

69

70

71

72

73

74

75

76

77

78

79

80

81

82

83

84

85

86

87

88

89

90

91

92

93

94

95

96

97

98

99

100

101

102

103

104

105

106

107

108

109

110

111

112

113

114 larger spatial or temporal scales. Thus, additional approaches are needed to complement classic biodiversity data, especially with respect to a better scaling and resolving the state and change of biodiversity. Approaches can be based on novel technological advances, such as in molecular sciences, or in a more detailed use of predictive or other statistical models (Guisan and Zimmermann 2000; Taberlet et al. 2012; Petchey et al. 2015; Altermatt et al. 2020). The implementation of these approaches, however, needs to be complemented with a thorough analysis of strengths and weaknesses, including directly comparing performance of the approaches as well as identifying what can (or cannot) be gained by either approach. Within the last decade, environmental DNA (eDNA) has been - especially in aquatic ecosystems - presented as a game-changer to traditional approaches, with the promise of being able to monitor biodiversity at unprecedented spatial and temporal scales (Hering et al., 2018; Leese et al., 2016, Deiner et al. 2017). In streams and rivers, it has also already been extensively used and compared to classic kicknet-based approaches, and complementarity and respective advantages and disadvantages have been put forward (e.g. Mächler et al., 2019, Hänfling et al., 2016, Pont et al. 2018). Several recent meta-analyses (Keck et al. 2021; McElroy et al. 2020) showed that, in aquatic environments, eDNA metabarcoding and traditional methods can provide similar estimates of taxonomic richness, but large inconsistencies remain in the taxonomic composition found by the two approaches, especially in macroinvertebrate and microbial communities.

A pairwise comparison of methods, however, may be hard to resolve, as either method could be a better approximation of reality. Thus, including a third approach, using a triad of comparisons (Figure 1), offers the possibility to resolve such discussions, yet hinges on models that rely on independent and exogenous variables (e.g. environmental variables) to predict diversity (see e.g. Moraes et al. 2014; Lobo et al. 2004; Lehmann et al. 2002). This latter approach does not estimate diversity from direct observation but from mathematical functions or statistical relationships previously established (Ferrier and Guisan 2006). Since direct observations (traditional or DNA-based) are still very sparse and limited, this third approach is the only one that currently allows us to estimate biodiversity on a large scale and in a continuous manner. However, there has been little - if any - work on linking the estimates obtained by such models (usually trained with traditional observational data) with those obtained from eDNA.

In this study, we used a dataset of 24 streams located in Switzerland, for which macroinvertebrate communities have been sampled at one location, both by kicknet and eDNA, and for which independent predictions on species richness have been modelled. We specifically focus on the diversity of three orders of macroinvertebrates: mayflies (Ephemeroptera, E), stoneflies (Plecoptera, P), and caddisflies (Trichoptera, T). EPT taxa are commonly found in streams and rivers, and have proven to be useful and powerful indicators of water quality (Wallace et al. 1996). We amplified eDNA with two distinct pairs of primers, a more generic one (mICOlintF/HCO2198, Leray et al. 2013, Folmer et al. 1994) and one more specific toward benthic invertebrate taxa (fwhF2/EPTDr2n, Vamos et al. 2017, Leese et al. 2021), in order to test their respective capacity to unveil EPT diversity. We compared the diversity estimates and the species composition detected by the eDNA and kicknet approaches, both at regional (gamma diversity) and local (alpha diversity) scale. We then related these results to the diversity estimated by a predictive statistical model for EPT richness (Kaelin and Altermatt 2016). Our goal was to evaluate the ability of this triad of methods to estimate and characterize the biodiversity in streams, and to investigate their differences. 


\section{Material and Methods}

116

117

118

119

120

121

122

123

124

125

126

127

128

129

130

131

132

133

134

135

136

137

138

139

140

141

142

143

144

145

146

147

148

149

150

151

152

153

154

155

156

157

158

159

160

\section{Sampling}

Water samples were collected from 24 streams in Switzerland in 2013-2014 (Figure 2). All streams were small to medium sized streams (range of catchment area 7 to $66 \mathrm{~km}^{2}$ ) in the Plateau and Jura part of Switzerland, covering an elevational range from 370 to $912 \mathrm{~m}$ a.s.l. All were headwater streams with no waste water treatment plants upstreams, and land-use types in the upstream catchment consisted mostly of forest and agriculture (dairy farming and cropping). Settlements covered between 5 and $21 \%$ of the catchment areas. At each location, we sampled two sites in the stream located a few hundreds meters apart, yet within the same habitat type and environmental conditions. Macroinvertebrate communities were sampled using kicknets and water samples were collected for eDNA analyses. Water samples were transported in a cooler on ice (maximum transport time of six hours) and were stored at $-20{ }^{\circ} \mathrm{C}$ until processed further. All samples were taken within a larger research program (for details of the project and sampling procedure, see also Burdon et al. 2019, Stamm et al. 2016, 2017). Here we focus on the subset of samples taken upstream of waste water treatment plant inflows only.

\section{EPT identification}

At each location, all individuals of may-, stone-, and caddisflies (EPT) were identified to the species level (in few cases to pre-defined species complexes, subsequently treated as species) using expert taxonomists. Identification of all taxa followed pre-defined taxonomic lists, and all data from the two sites per location were pooled. For details see Burdon et al. (2019) and Stucki (2010). For subsequent analyses, we only used presence/absence data, and calculated species richness values per location.

\section{Water filtration and DNA extraction}

Methods for filtration and extraction of DNA from water samples were previously published in Mansfeldt et al. (2020). Briefly, water was filtered through a glass fiber filter (GF/F, nominal pore size of $0.7 \mu \mathrm{m}, 25 \mathrm{~mm}$, Whatman International Ltd., England) and was extracted with a Phenol-Chloroform Isoamyl followed by an ethanol precipitation (Mansfeldt et al. 2020). Strict adherence to contamination control was followed using a controlled lab where only eDNA isolation and pre-PCR preparations are performed (Deiner et al. 2015). Between two and eight independent extractions from filters were carried out for each sample location. Total volume of water filtered for each extraction depended on the suspended solids in the sample, which clogged the filter, and ranged from 65 to $350 \mathrm{~mL}$. A total of 500 to $700 \mathrm{~mL}$ of filtered water was used per sample for DNA extraction (see Mansfeldt et al. 2020). A $50 \mu \mathrm{L}$ pool was created by adding equal volumes from each independent extraction and quantified using the Qubit (1.0) fluorometer following recommended protocols for the dsDNA HS Assay, which has a high accuracy for double stranded DNA between $1 \mathrm{ng} / \mathrm{mL}$ to $500 \mathrm{ng} / \mathrm{mL}$ (Life Technologies, Carlsbad, CA, USA). Filter negative controls were created for each day that filtration took place. A filter negative control consisted of filtering $250 \mathrm{~mL}$ of Milli-QB water that was secondarily decontaminated with UVC light. DNA extraction controls were used to monitor contamination and processed with each batch of extractions of which consisted of between 18 and 22 filters per batch (Table SXX: Controls tab). All pooled DNA extractions were cleaned with the OneStepTM PCR Inhibitor Removal Kit (Zymo Research, Irvine, California, USA) according to the manufacturer's protocol as this has been shown to be effective for removal of PCR inhibition of riverine samples of environmental DNA (McKee et al. 2015). 


\section{Library construction and sequencing}

162

163

164

165

166

167

168

169

170

171

172

173

174

175

176

177

178

179

180

181

182

183

184

185

186

187

188

189

190

191

192

193

194

195

196

197

198

199

200

201

202

203

204

205

206

207

208

209

210
Library construction for each sample location followed a three step PCR process. The first PCR consisted of amplification of a $312 \mathrm{bp}$ fragment of the 5' end of the Cytochrom Oxidase I mitochondrial gene (COI) using the forward primer (mICOlintF) from Leray et al. (2013) and the reverse primer (HCO2198) from Folmer et al. (1994). Four independent PCRs on eDNA were carried out in $15 \mu \mathrm{L}$ volumes with final concentrations of $1 \mathrm{x}$ supplied buffer (Faststart TAQ, Roche, Inc., Basel, Switzerland), $1000 \mathrm{ng} / \mu \mathrm{L}$ BSA (New England Biolabs, Ipswich, MA, USA), $0.2 \mathrm{mMol}$ dNTPs, $2.0 \mathrm{mMol} \mathrm{MgCl}$, 0.05 units per $\mu \mathrm{L}$ Taq DNA polymerase (Faststart $\mathrm{TAQ}$, Roche, Inc., Basel, Switzerland), and $0.5 \mu \mathrm{Mol}$ of each forward and reverse primer. 2 $\mu \mathrm{L}$ of extracted eDNA was added that ranged in concentration from 0.03 to $54.0 \mathrm{ng} / \mu \mathrm{L}$. This range was the outcome of DNA concentrations that were extracted. The thermal-cycling regime was $95^{\circ} \mathrm{C}$ for 4 minutes, followed by 35 cycles of $95^{\circ} \mathrm{C}$ for 30 seconds, $48{ }^{\circ} \mathrm{C}$ for 30 seconds and $72{ }^{\circ} \mathrm{C}$ for 1 minute. A final extension of $72{ }^{\circ} \mathrm{C}$ for 5 minutes was carried out and the PCR was cooled to $4^{\circ} \mathrm{C}$ until removed and stored at $-20^{\circ} \mathrm{C}$ until products were cleaned. PCR products were visualized on a $1.5 \%$ agarose gel to confirm amplification. We cleaned each PCR replicate with Exo I Nuclease (EXO I) and Shrimp Alkaline Phosphatase (SAP) (Thermo Fisher Scientific Inc., Waltham, Maryland USA). The master mix consisted of 1.6 $\mathrm{U} / \mu \mathrm{L}$ Exo I and $0.15 \mathrm{U} / \mu \mathrm{L}$ SAP in a total volume of $1.1 \mu \mathrm{L}$ which was then added to $7.5 \mu \mathrm{L}$ of the PCR product. Products were heated to $37^{\circ} \mathrm{C}$ for 15 minutes and followed by 15 minutes at $80{ }^{\circ} \mathrm{C}$ for deactivation of EXO and SAP.

The second PCR was conducted with the same PCR conditions above except the forward and reverse primers were modified to include the Nextera ${ }^{\circledR}$ transposase adaptors and only 1 $\mu \mathrm{L}$ of cleaned PCR product was used in the reaction. Between the forward and reverse primer sequence and the transposase adaptor a different number of random bases were inserted to create products of varying length to allow more heterogeneity on the flow cell. The thermal-cycling regime was the same except that five cycles were used. PCR products from the four independent reactions for each sample were then pooled together and cleaned using a two-step method. First, we cleaned each pooled reaction with EXO I and SAP as described above except we adjusted proportionally the volumes of EXO I and SAP for a total cleaned volume of $30 \mu \mathrm{L}$ rather than $7.5 \mu \mathrm{L}$. Second, we desalted, removed buffer components with the Illustra MicroSpin S-300 HR Columns (GE Healthcare Life Sciences, Little Chalfont, United Kingdom) following the manufacturer's recommended protocol.

The third PCR was to index each pooled PCR by before pooling all PCR from each site for sequencing. We duel-indexed samples using the Nextera ${ }^{\circledR}$ index kits $A$ and D. PCR was carried out in $50 \mu \mathrm{L}$ were samples were added at either 5 or $10 \mu \mathrm{L}$, where amplicons that showed a DNA concentration less than $0.1 \mathrm{ng} / \mu \mathrm{L}$ were added at $10 \mu \mathrm{L}$ and all other greater than this were added at $5 \mu \mathrm{L}$. We used the KAPA Library Amplification Kit following the manufacturer's recommended protocol (KAPA Biosystems, Wilmington, MA). Each of the pooled reactions were then cleaned using Agencourt AMPure XP beads following the recommended manufacturer's protocol (Beckman Coulter, Brea, CA, USA).

Cleaned and indexed libraries were then assayed for DNA concentration using the Qubit (1.0) fluorometer following recommended protocols for the dsDNA HS Assay, normalized then pooled at a $2 \mathrm{nM}$ concentration. PHiX control was added at $1 \%$. Paired-end sequencing was performed on an Illumina MiSeq (MiSeq Reagent kit v2, 250 cycles) at the Genomic Diversity Center at the ETH, Zurich, Switzerland following manufacturer's run protocols (Illumina, Inc., San Diego, CA, USA). The MiSeq Control Software Version 2.2 including MiSeq Reporter 2.2 was used for the primary analysis and the demultiplexing of the raw reads.

In order to amplify the $142 \mathrm{bp}$ long fragment of the COI locus using fwhF2 forward primer (Vamos et al. 2017) and EPTDr2n reverse primer (Leese et al. 2021) a similar three-step 
211 PCR as described above, was conducted. First PCR was carried out in three independent 212 PCR reactions with a total volume of $25 \mu \mathrm{L}$ containing final concentrations of $1 \mathrm{x}$ supplied buffer (Faststart TAQ, Roche, Inc., Basel, Switzerland), $1500 \mathrm{ng} / \mu \mathrm{L}$ BSA (Molecular biology grade, New England Biolabs), $0.2 \mathrm{mMol}$ dNTPs, $3.0 \mathrm{mMol} \mathrm{MgCl} 2,0.05$ units per $\mu \mathrm{L}$ Taq DNA polymerase (Faststart TAQ, Roche, Inc., Basel, Switzerland), and $0.5 \mu \mathrm{Mol}$ of each forward and reverse primer. $2 \mu \mathrm{L}$ of extracted eDNA or PCR grade water as negative control was added to each reaction. PCR Reactions were performed with the following cycle settings on a (Biometra T1Thermocycler, Analytik Jena $\mathrm{GMBH}, \mathrm{Ge}$ ): denaturation was at $95^{\circ} \mathrm{C}$ for 8 minutes, followed by 30 cycles of $95^{\circ} \mathrm{C}$ for 30 seconds, $50{ }^{\circ} \mathrm{C}$ for 1 minute and $72^{\circ} \mathrm{C}$ for 1 minute. A final extension of $72{ }^{\circ} \mathrm{C}$ for 7 minutes was performed, followed by lowering the temperature to $4^{\circ} \mathrm{C}$ to avoid DNA degrading.

From the first PCR product, $10 \mu \mathrm{L}$ was enzymatically cleaned by adding $0.11 \mathrm{U} / \mu \mathrm{L}$

Exonuclease I (E. coli), $0.2 \mathrm{U} / \mu \mathrm{L}$ Shrimp Alkaline Phosphatase (rSAP) (New England Biolabs) and $1.11 \mu \mathrm{L}$ PCR grade water to each sample. The temperature cycling was carried out, as recommended by the manufacturer.

In order to add the Nextera transposase sequences adaptors to the first PCR fragment, $4 \mu \mathrm{L}$ cleaned PCR product was used in similar PCR condition as in the first PCR reaction. Thermal cycling regime was identical, except that the number of cycles were reduced. Amplification success was checked with the AM320 method on the QiAxcel Screening Cartridge (Qiagen, Germany). Most of the samples worked after 10 PCR cycles. However, the cycling number for 28 samples was adjusted up to 18 cycles, in order to see amplification success.

Before we attached the index adapters with the third PCR, additional cleaning steps were performed. This consisted of first pooling the replicates of the second PCR product and then running it on a $0.8 \%$ low melting point Agarose (Analytical grade, Promega) together with 100 -bp ladders (Promega, Madison, WI, USA). Fragments with the correct size of $268 \mathrm{bp}$ were cutted out from gel, by using a fresh scalpel. Thereafter DNA was purified, using the Wizard SV Gel and PCR Clean-Up System (Promega, Madison, WI, USA). Exciseds DNA bands were dissolved in $250 \mu \mathrm{L}$ Membrane Binding Solution at $65^{\circ} \mathrm{C}$ shaken at $850 \mathrm{rpm}$ for 2 minutes. After the column bind and washing steps, DNA was eluted in $20 \mu \mathrm{L}$ PCR grade water.

Illumina Nextera XT Index set D (Illumina, Inc., San Diego, CA, USA) were attached to the purified amplicon by following the recommended protocol from the Illumina library preparation guide, except increasing cycle number from 8 to 10 cycles. After the Nextera® index adapters successfully bound to the fragment, the individual samples were cleaned up with a MagJET NGS Cleanup and Size Selection Kit running on a KingFisher Flex Purification System (Thermo Fisher Scientific Inc., MA, USA). Qubit BR DNA Assay Kit (Life Technologies, Carlsbad, CA, USA). Fluorescence dye emission of the standard dilution series and samples were measured in replicates with a Spark Multimode Microplate Reader (Tecan, US Inc., USA). Samples, including filter, extraction and PCR controls were then merged in four equimolar pools $(3 \mathrm{nM})$, in relation to their concentration, with an automated liquid handling station (BRAND GMBH $+\mathrm{CO} K G$, Wertheim, GE). Final pool was then three times manually purified, by using a $0.8 \mathrm{x}$ ratio of Agencourt AMPure XP (Beckman Coulter, Brea, CA, USA) beads, again following the recommended manufacturer's protocol. Amplicon size was verified by an Agilent 4200 TapeStation (AgilentTechnologies, Inc., USA) run. Library was sequenced with a concentration of $10 \mathrm{pM}$ in the flowcell on an Illumina MiSeq (Illumina, Inc. San Diego, CA, USA) at the Genetic Diversity Center (ETH, Zurich). The Sequencing run (MiSeq Reagent kit v2, 300 cycles, paired-ended) was spiked with $10 \%$ PHiX control. 


\section{Bioinformatics}

262 The software package DADA2 v.1.16.0 was used to infer amplicon sequence variants (ASVs) from the demultiplexed MiSeq (forward and reverse) reads following the methods described by Callahan et al. (2016). Primer sequences (mICOlintF/HCO2198 and fwhF2/EPTDr2n) were removed from the reads using cutadapt v.2.10 (Martin, 2011). After primer removal, the forward and reverse reads were truncated to 200 and 170 nucleotides respectively for the $\mathrm{mICOlintF/HCO2198}$ run, in order to remove poor quality nucleotides at their extremities. Both the forward and reverse reads were truncated to 120 nucleotides for the fwhF2/EPTDr2n run. Reads were quality-filtered by removing any read with one or more ambiguities ("N") and any read with a maximum expected error (maxEE) larger than 2. After dereplication, ASVs were finally selected based on the error rates model determined by the DADA2 denoising algorithm and paired reads merged into one sequence using a minimum overlap of 12 bases. Potential chimeric sequences were removed using the de novo bimera detection algorithm implemented in DADA2.

We translated the ASV sequences into amino acids starting from the 2nd nucleotide and using the invertebrate mitochondrial code. Since $\mathrm{COI}$ is a coding sequence, it is not expected to find stop codons in the barcode region. Therefore, all the ASV sequences (2642 for the mICOlintF/HCO2198 primers, 2251 for the fwhF2/EPTDr2n primers) in which a stop codon was found were discarded. For the mICOlintF/HCO2198 run, a total of 140 additional ASVs which were found in relative proportion $>0.1 \%$ in one of the six negative controls were also discarded from all the samples. For the fwhF2/EPTDr2n run, only 2 ASV sequences were removed at this step (2 negative controls were used).

Taxonomic assignment of ASV sequences was achieved using the RDP algorithm (Wang et al. 2007) with a bootstrap threshold of $75 \%$. The reference database used for taxonomic assignment was assembled from several sources: NCBI, Bold, MIDORI and the EPT sequences collected within the SwissBOL project. After quality filtering (removing incorrect sequences and mislabeled taxa) the reference database included 654,132 labeled $\mathrm{COI}$ sequences divided in 88 classes, 493 orders, 4,107 families, 33,337 genera and 120,374 species. Replicates (sites) were merged by locations. For five locations (Buttisholz, Hochdorf, Hornussen, Messen, and Niederdorf, see Figure 2), only one replicate was available for mICOlintF/HCO2198. Therefore we excluded the corresponding replicates from the analysis of fwhF2/EPTDr2n.

\section{Predictive model for EPT richness}

294 For each sampling location, we predicted the EPT species richness using a statistical species distribution (species richness) model developed by Kaelin and Altermatt (2016), and model predictions were directly taken from that publication for the respective 24 study catchments used here. Briefly, this model is a generalized linear model using a Poisson error distribution. The model was trained to predict EPT species richness from a set of 11 environmental variables using lasso regularization. The model had been trained with a dataset of 410 independent locations where EPT species richness was assessed by kicknet sampling. These 410 locations did not overlap with any of the 24 study locations/catchments herein used, and had been monitored by kicknet in a systematic manner between 20092013, ensuring random spatial and temporal coverage (for details, see Altermatt et al. 2013, Ryo et al. 2018). These sites cover a much wider environmental, geographic and temporal scale than the 24 study catchments compared to, thus should encapsulate all variation in species richness expected in the latter. Then, using generalized linear models incorporating all main land-use variables identified as relevant by Kaelin \& Altermatt (2016), the model was used to predict species richness in 22,169 2 $\mathrm{km}^{2}$ large sub-catchments, covering the entire territory of Switzerland. Predictions on alpha diversity (richness) of EPT were retrieved for the sub-catchments corresponding to the 24 locations studied here. Thus, the predictive 
311

312

313

314

315

316

317

318

319

320

321

322

323

324

325

326

327

328

329

330

331

332

333

334

335

336

337

338

339

340

341

342

343

344

345

346

347

348

349

350

351

352

353

354

355

356

species distribution model made predictions on the expected richness in the 24 study catchments further analysed here are based on a model parametrized across all of Switzerland. We note that the data used to train the predictive model are also based on kicknet samples. That is, there may be an inherent part of diversity only detectable by eDNA that cannot be assessed by the kicknet method, which would thus also not be covered by the model. Importantly, however, the model makes only predictions at the level of total richness, and not at the level of individual species' identity. Thus, predictions are at a coarser level, such that this effect is not expected to play a major role, or maximally result in a shift in the intercept of richness predictions.

\section{Analyses}

We used presence-absence data and species richness (i.e. the number of species) to characterize the diversity of EPT, both from the eDNA as well as the kicknet data. Diversity was studied both at local scale (i.e. locations after merging site replicates, alpha diversity), and at regional scale (i.e. all locations merged, gamma diversity). For both alpha and gamma diversity, we compared the number of species detected by kicknet only, by eDNA only, and by the two approaches simultaneously. For each location, the sampling effort (number of identified individuals and sequencing depth) was assessed with species accumulation curves. Finally, we computed and tested Pearson correlations between the richness found by eDNA (fwhF2/EPTDr2n and mICOlintF/HCO2198 primers separately), found by kicknet and estimated by the predictive model. Analyses were conducted using $\mathrm{R}$ 4.0.3 (R Core Team, 2020).

\section{Data and code}

All raw sequencing data are available at the European Nucleotide Archive (ENA) under the accession number PRJEB26649. The processed data and $\mathrm{R}$ scripts to reproduce the analyses and results are available at : https://github.com/fkeck/ecoimpact.

\section{Results}

Library sequencing generated 4,638,809 sequences (mICOlintF/HCO2198 primers) and $8,008,677$ sequences (fwhF2/EPTDr2n primers). For sequences amplified using the $\mathrm{mICO}$ lintF/HCO2198 primers, the pre-processed and quality-filtered data consists of $3,110,057$ reads divided in 13,797 ASVs. For sequences amplified using the fwhF2/EPTDr2n primers, the pre-processed and quality-filtered data consists of 4,779,863 reads divided in 2,665 ASVs.

For the mICOlintF/HCO2198 primers, taxonomic assignment failed for a significant number of ASVs for which identification was not possible, even at the highest taxonomic ranks $(87 \%$ of unclassified Eukaryota). Assigned reads are dominated by insects (Diptera, Coleoptera and unclassified Insecta), Clitellata, Chromadorea and unclassified arthropods. The orders of interest (EPT) only represent a small proportion of assigned ASVs (7\%), with 32 Ephemeroptera, 17 Plecoptera and 34 Trichoptera taxa detected. The relative proportion of EPT is even less important when accounting for the number of reads. In total the EPT groups represent $3.1 \%$ of the assigned reads. In contrast, the fwhF2/EPTDr2n primers performed better with a lower proportion of unidentified Eukaryota (47.9\%). Targeted orders were also more represented with 63 ASVs identified as Ephemeroptera, 37 as Plecoptera, and 42 as Trichoptera taxa, representing $10 \%$ of the assigned ASVs (8.6\% of the assigned reads). The sampling depth (number of reads identified as EPT) was highly variable among locations (ranging from 7 at Aadorf with mICOlintF/HCO2198 to 109,956 at Zullwil with fwhF2/EPTDr2n). The absolute number of reads identified as EPT was 10 to 100 times 
357 higher with the fwhF2/EPTDr2n primers than with the mICOlintF/HCO2198 primers 358 (Supplementary Information Figure 1 and 2). In one location (Hornussen) none of the tested 359 primers could detect EPT taxa. However, all the species accumulation curves seem to reach 360 a plateau in the other locations (Supplementary Information Figure 1 and 2). This was not 361 the case with the kicknet data (Supplementary Information Figure 3).

362 Across all sites (i.e., gamma diversity), kicknet was the method that detected the highest 363 number of different EPT taxa (64), followed by eDNA amplified with the fwhF2/EPTDr2n primers (44 taxa). Results of the regional EPT species richness (across all locations) are shown on Figure 3. Environmental DNA amplified by the mICOlintF/HCO2198 primers detected only 28 taxa across all sites. In total, 16 taxa were detected by the three methods. We found a better congruence between the fwhF2/EPTDr2n primers and the kicknet (32 common taxa) than between the mICOlintF/HCO2198 primers and the kicknet $(21$ common taxa), or between the two primers (21 common taxa).

The number of EPT taxa detected varied both across locations and methods (Figure 4). Additionally, the mICOlintF/HCO2198 primers did not detect any EPT taxa in three other locations (Buttisholz, Knonau and Rothenthurm). Some locations showed particularly poor diversity (e.g. Colombey, Val de Ruz), while others exhibited a high EPT richness (e.g. Rothenthurm when assessed with the fwhF2/EPTDr2n primers). Overall, alpha diversity (local species richness) was higher with kicknet (mean $=19.6, \mathrm{sd}=6.5$ ) than with eDNA amplified with mICOlintF/HCO2198 primers (mean $=4.37$, $\mathrm{sd}=3.85$ ) or fwhF2/EPTDr2n primers (mean $=7, s d=7.88$ ). The mean richness detected by the fwhF2/EPTDr2n primers was not significantly higher than the mean richness detected by the mICOlintF/HCO2198 primers (paired t-test, $\mathrm{t}=-1.48, \mathrm{p}$-value $=0.15$ ).

Some taxa commonly detected by kicknet sampling were never or rarely detected by eDNA (Figure 5). For example, this is the case for Alainites muticus, Centroptilum luteolum, Habrophlebia lauta or the genus Hydropsyche. Contrastingly, the very common species Baetis rhodani was well detected by both approaches. There is no common species detected systematically by eDNA that is not detected by the traditional sampling. However, a few species were detected only by eDNA in a few streams (e.g. Glyphotaelius pellucidus, Nemurella pictetii, and the Hydroptila-complex).

387 We found the correlation between the richness estimates provided by the different methods 388 to be remarkably low (Figure 6 ). The highest correlation (rho $=0.44$, $p$-value $=0.03$ ) was 389 found between the predictive model and eDNA amplified with the fwhF2/EPTDr2n primers. Correlations between the kicknet method and the predictive model (rho $=0.3, p$-value $=$ 0.16 ) and between the kicknet method and the fwhF2/EPTDr2n primers (rho $=0.27, \mathrm{p}$-value $=0.2$ ) were not significant. The correlations between the mICOlintF/HCO2198 primers and the other approaches were close to zero and non-significant (Figure 6). Merging the primers did not improve the correlations between the richness found by eDNA and the other methods (Supplementary Information Figure 4).

\section{Discussion}

The study of diversity on a regional scale (gamma diversity) shows the ability of environmental DNA to detect many taxa also identified by the traditional kicknet method. This result is in line with previous studies which reported several EPT taxa detected by both methods (Mächler et al. 2019, Seymour et al. 2021). However, a significant number of taxa known to be present in these rivers (according to the kicknet sampling) could not be detected by either the mICOlintF/HCO2198 or fwhF2/EPTDr2n primers. In total, 23 EPT species were detected by kicknet and were not detected by either primer set. The noncongruence between kicknet and the eDNA methods is even more pronounced when results are assessed at local scale (alpha diversity). This result is not surprising, as pooling species 
406 information from multiple locations together across a region is likely to increase the set of metabarcoding studies to perform comparisons at regional level (i.e. gamma diversity), which probably contributed to a misleading idea that eDNA and traditional methods are generally congruent. A recent meta-analysis showed, on the contrary, the low congruence between species list generated by DNA metabarcoding and traditional methods for macroinvertebrates (Keck et al. 2021). Thus, while numbers of diversity reported may be similar, the identity of taxa found by each method can substantially differ.

414 Overall, we observed a low correlation between the diversity measures estimated by the triad of different tested methods (kicknet, eDNA and model predictions). The highest correlation was found between eDNA (fwhF2/EPTDr2n primers) and the predictive model. This relationship might be to some degree driven by the fact that both methods reflect diversity at catchment scale as eDNA integrates to some point EPT diversity at the catchment level (Deiner et al. 2016) and the model estimates EPT diversity from multiple variables, catchment-wise (Kaelin and Altermatt 2016). The low correlations observed between the diversity measures estimated by the different methods can largely be explained by the methodological biases discussed above. It should also be noted that the locations studied have been sampled across a relatively limited gradient in river size (all were small to mid sized rivers), all between 370 to $912 \mathrm{~m}$ a.s.I. Therefore, the expected variation in the number of EPT species is limited and this reduces our ability to detect statistical relationships between the different methods. However, the variability in land-use in the catchments was relatively pronounced, such that arable land ranged between 0.1 and $81 \%$, urban areas between 5 and $21 \%$, and grassland between 4 and $54 \%$. The main goal of our study, namely to use independent model predictions from a species distribution model (Kaelin \& Altermatt 2016) to evaluate the accuracy of kicknet vs. eDNA approaches through a third, independent approach was only partially successful: indeed, the triad of approaches gave a triad of partially congruent and partially complementary results. The low congruence between the species detected by eDNA and kicknet can be explained by the numerous biases that can influence species detection probabilities at every step of data collection. For eDNA this can be caused by the complex dynamics of DNA in the environment (release rate by the organisms, degradation and dilution), manipulation of the DNA in the lab (conservation, extraction, PCR-amplification, sequencing), and the bioinformatics processing (Deiner et al. 2017). For the traditional methods, possible biases may concern sampling representativity (Larras and Usseglio-Polatera 2020) and taxonomic identification, including both errors and lack of precision (Stribling et al. 2008). However, the respective role of these factors remains difficult to disentangle and to estimate.

442 One of the reasons often cited to explain the non-detection of taxa by DNA methods is the difficult to evaluate, is perfectly valid in studies dealing with the diversity of large or poorly known taxonomic groups (Lindeque et al. 2013). In the present study, this hypothesis can be excluded as all species detected by kicknet (except one) are present in the reference database used. However, this does not guarantee that the amplified regions can resolve all species detected by kicknet, nor that the intra-specific diversity of these species is fully represented in our reference database.

It should be noted that the choice of the primers and the barcode region to be amplified seems to play a significant role here. Overall, we found that fwhF2/EPTDr2n primers detected more EPT taxa than the mICOlintF/HCO2198 primers. It appears that the taxa detected by the mICOlintF/HCO2198 primers are in majority nested within the pool of taxa detected by the fwhF2/EPTDr2n primers, which is not surprising given that they are both amplifying a region of the same marker (COI). Hence our results confirm that for a group of organisms like the EPT, primer performance changes the detection rate on the exact same extracted eDNA sample. The fwhF2/EPTDr2n primers do have a higher target to non-target 
458 ratio for EPT compared to $\mathrm{mlCO}$ lintF/HCO2198 primers (but see Leese et al. 2021 for 459 results and discussion for all benthic macroinvertebrates).

460 The fact that the more specific primers outperformed the less specific ones raises another 461 important question: how many EPT species could not be correctly detected by the 462 fwhF2/EPTDr2n primers because of their lack of specificity? It should be remembered that 463 these primers, although more specific than the mICOlintF/HCO2198 primers, cover a 464 paraphyletic and very large group of organisms (basically, all insects, of which EPT make 465 only a small percentage). Therefore, gains in the number of species detected by eDNA could 466 be expected by using markers and primers specific to these three polyphyletic groups.

467 The large number of taxa detected only by the kicknet method should not mask the 468 existence of several taxa that were detected only by their DNA. This result highlights the fact 469 that DNA can provide real added value to traditional sampling techniques (Sweeney et al. 470 2011). The presence of these taxa can be explained on the one hand by the integrative aspect of environmental DNA, which reflects diversity on a larger scale via transport of DNA from upstream to downstream of the watershed (Deiner \& Altermatt, 2014), and on the other hand by the capacity of DNA to identify species that are sometimes difficult to collect or identify using morphological criteria (Haase et al. 2006, Stribling et al. 2008).

475

476

477

478

479

In conclusion, our results suggest that the three approaches investigated here can give very different results about the species richness and the species composition of EPT communities. These differences are due to the respective biases of each method, but also to the different scales that they integrate. Kicknet sampling is carried out at one point and captures the organisms physically present at that location. In contrast, models typically provide estimates of macroinvertebrate diversity on a regular grid or at catchment level (Ferrier and Guisan 2006). Finally, environmental DNA is sampled at one point but has the characteristic of being transported from upstream to downstream, thus integrating diversity at the catchment scale (Deiner \& Altermatt, 2014; Deiner et al. 2016). Therefore, although a certain degree of congruence is expected between the estimates produced by these methods, their different nature (observation vs. modelling) and the scales they incorporate can produce variable results, as shown here. Importantly, new frameworks integrating hydrological transport dynamics of eDNA allow to derive higher resolution diversity predictions and may act as a bridge between these methods (Carraro et al. 2020), yet have hitherto only been applied to catchments/scales larger than studied here. More efforts are needed to understand the reason why we observe such differences and additional work is needed to improve compatibility and comparability between them. However the achievable congruence between these approaches is currently limited as each comes with its own specificities, strengths and weaknesses. On the one hand, kicknet sampling and morphological identification and modeling are not likely to see major advancements that would change the outcome of our analysis. Whereas on the other hand, analysis of eDNA for macroinvertebrates still suffers from major drawbacks due to their paraphyletic origin and difficulty to exclude non-target groups during genetic analysis. Thus eDNA metabarcoding has the greatest potential for advancement through further method development and research. Here we showed that simply by changing primer sequences we could already improve correlation with the model. Regardless, until this challenge is solved, the three methods provide different perspectives on biological diversity and should be used together to provide complementary information to make informed decisions related to biodiversity management and conservation.

\section{Acknowledgements}

505 We thank Marta Reyes for help during field work, Francis J. Burdon and Rik Eggen for 506 comments on the project and coordination, and Pascal Stucki for sampling and identification 
507 of the EPT taxa. This work has been funded by the Swiss Federal Office for the Environment 508 (BAFU/FOEN) and is part of the Eawag Ecoimpact initiative. Further funding is from The 509 Swiss National Science Foundation (grant nr. 31003A 173074), the University of Zurich 510 Research Priority Programme in Global Change and Biodiversity (URPP GCB) to FA and the 511 European Research Council (ERC) under the European Union's Horizon 2020 research and 512 innovation programme (Grant agreement No. 852621) to KD.

\section{References}

514 Altermatt F, Seymour M, Martinez N (2013) River network properties shape a-diversity and 515 community similarity patterns of aquatic insect communities across major drainage basins. 516 Journal of Biogeography 40: 2249-2260. https://doi.org/10.1111/jbi.12178

517 Altermatt F, Little CJ, Mächler E, Wang S, Zhang X, Blackman RC (2020) Uncovering the 518 complete biodiversity structure in spatial networks: the example of riverine systems. Oikos 519 129: 607-618. https://doi.org/10.1111/oik.06806

520 Burdon FJ, Munz NA, Reyes M, Focks A, Joss A, Räsänen K, Altermatt F, Eggen RIL, 521 Stamm C (2019) Agriculture versus wastewater pollution as drivers of macroinvertebrate 522 community structure in streams. Science of The Total Environment 659: 1256-1265. 523 https://doi.org/10.1016/j.scitotenv.2018.12.372

524 Callahan BJ, McMurdie PJ, Rosen MJ, Han AW, Johnson AJA, Holmes SP (2016) DADA2: 525 High-resolution sample inference from Illumina amplicon data. Nature Methods 13: 581-583. 526 https://doi.org/10.1038/nmeth.3869

527 Cardinale BJ, Duffy JE, Gonzalez A, Hooper DU, Perrings C, Venail P, Narwani A, Mace 528 GM, Tilman D, Wardle DA, Kinzig AP, Daily GC, Loreau M, Grace JB, Larigauderie A, 529 Srivastava DS, Naeem S (2012) Biodiversity loss and its impact on humanity. Nature 486: 530 59-67. https://doi.org/10.1038/nature11148

531 Carraro L, Mächler E, Wüthrich R, Altermatt F (2020) Environmental DNA allows upscaling 532 spatial patterns of biodiversity in freshwater ecosystems. Nature Communications, 11: 3585. 533 https://doi.org/10.1038/s41467-020-17337-8

534 Chapin III FS, Zavaleta ES, Eviner VT, Naylor RL, Vitousek PM, Reynolds HL, Hooper DU, 535 Lavorel S, Sala OE, Hobbie SE, Mack MC, Díaz S (2000) Consequences of changing 536 biodiversity. Nature 405: 234-242. https://doi.org/10.1038/35012241

537 Deiner K, Altermatt F (2014) Transport Distance of Invertebrate Environmental DNA in a 538 Natural River. PLOS ONE 9: e88786. https://doi.org/10.1371/journal.pone.0088786

539 Deiner K, Walser J-C, Mächler E, Altermatt F (2015) Choice of capture and extraction 540 methods affect detection of freshwater biodiversity from environmental DNA. Biological 541 Conservation 183: 53-63. https://doi.org/10.1016/j.biocon.2014.11.018

542 Deiner K, Fronhofer EA, Mächler E, Walser J-C, Altermatt F (2016) Environmental DNA 543 reveals that rivers are conveyer belts of biodiversity information. Nature Communications 7 : 544 12544. https://doi.org/10.1038/ncomms 12544

545 Deiner K, Bik HM, Mächler E, Seymour M, Lacoursière $\square$ Roussel A, Altermatt F, Creer S, 546 Bista I, Lodge DM, Vere N de, Pfrender ME, Bernatchez L (2017) Environmental DNA 547 metabarcoding: Transforming how we survey animal and plant communities. Molecular 548 Ecology 26: 5872-5895. https://doi.org/10.1111/mec.14350 
549 Díaz S, Zafra-Calvo N, Purvis A, Verburg PH, Obura D, Leadley P, Chaplin-Kramer R, De 550 Meester L, Dulloo E, Martín-López B, Shaw MR, Visconti P, Broadgate W, Bruford MW, 551 Burgess ND, Cavender-Bares J, DeClerck F, Fernández-Palacios JM, Garibaldi LA, Hill SLL, 552 Isbell F, Khoury CK, Krug CB, Liu J, Maron M, McGowan PJK, Pereira HM, Reyes-García V, 553 Rocha J, Rondinini C, Shannon L, Shin Y-J, Snelgrove PVR, Spehn EM, Strassburg B, 554 Subramanian SM, Tewksbury JJ, Watson JEM, Zanne AE (2020) Set ambitious goals for 555 biodiversity and sustainability. Science 370: 411-413. 556 https://doi.org/10.1126/science.abe1530

557 Elbrecht V, Vamos EE, Meissner K, Aroviita J, Leese F (2017) Assessing strengths and 558 weaknesses of DNA metabarcoding $\square$ based macroinvertebrate identification for routine 559 stream monitoring. Yu D (Ed.). Methods in Ecology and Evolution 8: 1265-1275. 560 https://doi.org/10.1111/2041-210X.12789

561 Ferrier S, Guisan A (2006) Spatial modelling of biodiversity at the community level. Journal 562 of Applied Ecology 43: 393-404. https://doi.org/10.1111/j.1365-2664.2006.01149.x

563 Folmer O, Black M, Hoeh W, Lutz R, Vrijenhoek R (1994) DNA primers for amplification of 564 mitochondrial cytochrome c oxidase subunit I from diverse metazoan invertebrates. 565 Molecular Marine Biology and Biotechnology 3: 294-9.

566 Guisan A, Zimmermann NE (2000) Predictive habitat distribution models in ecology. 567 Ecological Modelling 135: 147-186. https://doi.org/10.1016/S0304-3800(00)00354-9

568 Haase P, Murray-Bligh J, Lohse S, Pauls S, Sundermann A, Gunn R, Clarke R (2006) 569 Assessing the impact of errors in sorting and identifying macroinvertebrate samples. In: 570 Furse MT, Hering D, Brabec K, Buffagni A, Sandin L, Verdonschot PFM (Eds), The 571 Ecological Status of European Rivers: Evaluation and Intercalibration of Assessment 572 Methods. Developments in Hydrobiology. Springer Netherlands, Dordrecht, 505-521. 573 https://doi.org/10.1007/978-1-4020-5493-8_34

574 Hänfling B, Lawson Handley L, Read DS, Hahn C, Li J, Nichols P, Blackman RC, Oliver A, 575 Winfield IJ (2016) Environmental DNA metabarcoding of lake fish communities reflects long576 term data from established survey methods. Molecular Ecology 25: 3101-3119. 577 https://doi.org/10.1111/mec.13660

578 Hering D, Borja A, Jones JI, Pont D, Boets P, Bouchez A, Bruce K, Drakare S, Hänfling B, 579 Kahlert M, Leese F, Meissner K, Mergen P, Reyjol Y, Segurado P, Vogler A, Kelly M (2018) 580 Implementation options for DNA-based identification into ecological status assessment 581 under the European Water Framework Directive. Water Research 138: 192-205. 582 https://doi.org/10.1016/j.watres.2018.03.003

583 Kaelin K, Altermatt F (2016) Landscape-level predictions of diversity in river networks reveal 584 opposing patterns for different groups of macroinvertebrates. Aquatic Ecology 50: 283-295. 585 https://doi.org/10.1007/s10452-016-9576-1

586 Keck F, Blackman RC, Bossart R, Brantschen J, Couton M, Hürlemann S, Kirschner D, 587 Locher N, Zhang H, Altermatt F (2021) Meta-analysis shows both congruence and 588 complementarity of DNA metabarcoding to traditional methods for biological community 589 assessment. 2021.06.29.450286pp. https://doi.org/10.1101/2021.06.29.450286

590 Larras F, Usseglio-Polatera P (2020) Heterogeneity in macroinvertebrate sampling strategy 591 introduces variability in community characterization and stream trait-based biomonitoring: 592 Influence of sampling effort and habitat selection criteria. Ecological Indicators 119: 106758. 593 https://doi.org/10.1016/j.ecolind.2020.106758 
594 Leese F, Sander M, Buchner D, Elbrecht V, Haase P, Zizka VMA (2021) Improved 595 freshwater macroinvertebrate detection from environmental DNA through minimized 596 nontarget amplification. Environmental DNA 3: 261-276. https://doi.org/10.1002/edn3.177

597 Leese F, Altermatt F, Bouchez A, Ekrem T, Hering D, Meissner K, Mergen P, Pawlowski J, 598 Piggott J, Rimet F, Steinke D, Taberlet P, Weigand A, Abarenkov K, Beja P, Bervoets L, 599 Björnsdóttir S, Boets P, Boggero A, Bones A, Borja Á, Bruce K, Bursić V, Carlsson J, 600 Čiampor F, Čiamporová-Zatovičová Z, Coissac E, Costa F, Costache M, Creer S, Csabai Z, 601 Deiner K, DelValls Á, Drakare S, Duarte S, Eleršek T, Fazi S, Fišer C, Flot J-F, Fonseca V, 602 Fontaneto D, Grabowski M, Graf W, Guðbrandsson J, Hellström M, Hershkovitz Y, 603 Hollingsworth P, Japoshvili B, Jones J, Kahlert M, Stroil BK, Kasapidis P, Kelly M, Kelly604 Quinn M, Keskin E, Kõljalg U, Ljubešić Z, Maček I, Mächler E, Mahon A, Marečková M, 605 Mejdandzic M, Mircheva G, Montagna M, Moritz C, Mulk V, Naumoski A, Navodaru I, 606 Padisák J, Pálsson S, Panksep K, Penev L, Petrusek A, Pfannkuchen M, Primmer C, 607 Rinkevich B, Rotter A, Schmidt-Kloiber A, Segurado P, Speksnijder A, Stoev P, Strand M, 608 Šulčius S, Sundberg P, Traugott M, Tsigenopoulos C, Turon X, Valentini A, Hoorn B van der, 609 Várbíró G, Hadjilyra MV, Viguri J, Vitonytè I, Vogler A, Vrålstad T, Wägele W, Wenne R, 610 Winding A, Woodward G, Zegura B, Zimmermann J (2016) DNAqua-Net: Developing new 611 genetic tools for bioassessment and monitoring of aquatic ecosystems in Europe. Research 612 Ideas and Outcomes 2: e11321. https://doi.org/10.3897/rio.2.e11321

613 Lehmann A, Leathwick JR, Overton JMcC (2002) Assessing New Zealand fern diversity from 614 spatial predictions of species assemblages. Biodiversity \& Conservation 11: 2217-2238. 615 https://doi.org/10.1023/A:1021398729516

616 Leray M, Yang JY, Meyer CP, Mills SC, Agudelo N, Ranwez V, Boehm JT, Machida RJ 617 (2013) A new versatile primer set targeting a short fragment of the mitochondrial COI region 618 for metabarcoding metazoan diversity: application for characterizing coral reef fish gut 619 contents. Frontiers in Zoology 10: 34. https://doi.org/10.1186/1742-9994-10-34

620 Lindenmayer DB, Likens GE (2010) The science and application of ecological monitoring. 621 Biological Conservation 143: 1317-1328. https://doi.org/10.1016/j.biocon.2010.02.013

622 Lindeque PK, Parry HE, Harmer RA, Somerfield PJ, Atkinson A (2013) Next Generation 623 Sequencing Reveals the Hidden Diversity of Zooplankton Assemblages. PLOS ONE 8: 624 e81327. https://doi.org/10.1371/journal.pone.0081327

625 Lobo JM, Jay-Robert P, Lumaret J-P (2004) Modelling the species richness distribution for 626 French Aphodiidae (Coleoptera, Scarabaeoidea). Ecography 27: 145-156. 627 https://doi.org/10.1111/j.0906-7590.2004.03609.x

628 Mächler E, Little CJ, Wüthrich R, Alther R, Fronhofer EA, Gounand I, Harvey E, Hürlemann 629 S, Walser J-C, Altermatt F (2019) Assessing different components of diversity across a river 630 network using eDNA. Environmental DNA 1:290-301. https://doi.org/10.1002/edn3.33

631 Mansfeldt C, Deiner K, Mächler E, Fenner K, Eggen RIL, Stamm C, Schönenberger U, 632 Walser J-C, Altermatt, F (2020) Microbial community shifts in streams receiving treated 633 wastewater effluent. Science of The Total Environment, 709: 135727. 634 https://doi.org/10.1016/j.scitotenv.2019.135727

635 Martin M (2011) Cutadapt removes adapter sequences from high-throughput sequencing 636 reads. EMBnet.journal 17: 10-12. https://doi.org/10.14806/ej.17.1.200

637 McElroy ME, Dressler TL, Titcomb GC, Wilson EA, Deiner K, Dudley TL, Eliason EJ, Evans 638 NT, Gaines SD, Lafferty KD, Lamberti GA, Li Y, Lodge DM, Love MS, Mahon AR, Pfrender 639 ME, Renshaw MA, Selkoe KA, Jerde CL (2020) Calibrating Environmental DNA 
640 Metabarcoding to Conventional Surveys for Measuring Fish Species Richness. Frontiers in 641 Ecology and Evolution 8: 276. https://doi.org/10.3389/fevo.2020.00276

642 McKee AM, Spear SF, Pierson TW (2015) The effect of dilution and the use of a post643 extraction nucleic acid purification column on the accuracy, precision, and inhibition of 644 environmental DNA samples. Biological Conservation 183: 70-76. 645 https://doi.org/10.1016/j.biocon.2014.11.031

646 Moraes MR, Ríos-Uzeda B, Moreno LR, Huanca-Huarachi G, Larrea-Alcázar D (2014) Using 647 Potential Distribution Models for Patterns of Species Richness, Endemism, and 648 Phytogeography of Palm Species in Bolivia. Tropical Conservation Science 7: 45-60. 649 https://doi.org/10.1177/194008291400700109

650 Pereira HM, Cooper DH (2006) Towards the global monitoring of biodiversity change. 651 Trends in Ecology \& Evolution 21: 123-129. https://doi.org/10.1016/j.tree.2005.10.015

652 Petchey OL, Pontarp M, Massie TM, Kéfi S, Ozgul A, Weilenmann M, Palamara GM, 653 Altermatt F, Matthews B, Levine JM, Childs DZ, McGill BJ, Schaepman ME, Schmid B, 654 Spaak P, Beckerman AP, Pennekamp F, Pearse IS (2015) The ecological forecast horizon, 655 and examples of its uses and determinants. Ecology Letters 18: 597-611. 656 https://doi.org/10.1111/ele.12443

657 Pont D, Rocle M, Valentini A, Civade R, Jean P, Maire A, Roset N, Schabuss M, Zornig H, 658 Dejean T (2018) Environmental DNA reveals quantitative patterns of fish biodiversity in large 659 rivers despite its downstream transportation. Scientific Reports 8: 10361. 660 https://doi.org/10.1038/s41598-018-28424-8

661 R Core Team (2020) R: A Language and Environment for Statistical Computing. R 662 Foundation for Statistical Computing, Vienna, Austria. Available from: https://www.R663 project.org/.

664 Ryo M, Harvey E, Robinson CT, Altermatt F (2018) Nonlinear higher order abiotic 665 interactions explain riverine biodiversity. Journal of Biogeography 45: 628-639. 666 https://doi.org/10.1111/jbi.13164

667 Seymour M, Edwards FK, Cosby BJ, Bista I, Scarlett PM, Brailsford FL, Glanville HC, de 668 Bruyn M, Carvalho GR, Creer S (2021) Environmental DNA provides higher resolution 669 assessment of riverine biodiversity and ecosystem function via spatio-temporal nestedness 670 and turnover partitioning. Communications Biology 4: 1-12. https://doi.org/10.1038/s42003$671 \quad 021-02031-2$

672 Stamm C, Räsänen K, Burdon FJ, Altermatt F, Jokela J, Joss A, Ackermann M, Eggen RIL 673 (2016) Unravelling the Impacts of Micropollutants in Aquatic Ecosystems: Interdisciplinary 674 Studies at the Interface of Large-Scale Ecology. In: Dumbrell AJ, Kordas RL, Woodward G 675 (Eds), Advances in Ecological Research. Large-Scale Ecology: Model Systems to Global 676 Perspectives. Academic Press, 183-223.

677 Stamm C, Burdon F, Fischer S, Kienle EC, Munz NA, Tlili A, Altermatt F, Behra R, 678 Bürgmann H, Joss A, Räsänen K, Eggen RIL (2017) Einfluss von Mikroverunreinigungen. 679 Aqua \& Gas, 6 17: 90-95.

680 Stribling JB, Pavlik KL, Holdsworth SM, Leppo EW (2008) Data quality, performance, and 681 uncertainty in taxonomic identification for biological assessments. Journal of the North 682 American Benthological Society 27: 906-919. https://doi.org/10.1899/07-175.1

683 Stucki P (2010) Methoden zur Untersuchung und Beurteilung der Fliessgewasser: 684 Makrozoobenthos Stufe F. Umwelt-Vollzug 1026. BAFU, Bern. 61 pp. 
685 Sweeney BW, Battle JM, Jackson JK, Dapkey T (2011) Can DNA barcodes of stream 686 macroinvertebrates improve descriptions of community structure and water quality? Journal 687 of the North American Benthological Society 30: 195-216. https://doi.org/10.1899/10-016.1

688 Taberlet P, Coissac E, Hajibabaei M, Rieseberg LH (2012) Environmental DNA. Molecular 689 Ecology 21: 1789-1793. https://doi.org/10.1111/j.1365-294X.2012.05542.x

690 Vamos E, Elbrecht V, Leese F (2017) Short COI markers for freshwater macroinvertebrate 691 metabarcoding. Metabarcoding and Metagenomics 1: e14625. 692 https://doi.org/10.3897/mbmg.1.14625

693 Wallace JB, Grubaugh JW, Whiles MR (1996) Biotic Indices and Stream Ecosystem 694 Processes: Results from an Experimental Study. Ecological Applications 6: 140-151. 695 https://doi.org/10.2307/2269560

696 Wang Q, Garrity GM, Tiedje JM, Cole JR (2007) Naïve Bayesian Classifier for Rapid 697 Assignment of rRNA Sequences into the New Bacterial Taxonomy. Applied and 698 Environmental Microbiology 73: 5261-5267. https://doi.org/10.1128/AEM.00062-07

699 Weigand H, Beermann AJ, Čiampor F, Costa FO, Csabai Z, Duarte S, Geiger MF, 700 Grabowski M, Rimet F, Rulik B, Strand M, Szucsich N, Weigand AM, Willassen E, Wyler SA, 701 Bouchez A, Borja A, Čiamporová-Zatovičová Z, Ferreira S, Dijkstra K-DB, Eisendle U, 702 Freyhof J, Gadawski P, Graf W, Haegerbaeumer A, van der Hoorn BB, Japoshvili B, 703 Keresztes L, Keskin E, Leese F, Macher JN, Mamos T, Paz G, Pešić V, Pfannkuchen DM, 704 Pfannkuchen MA, Price BW, Rinkevich B, Teixeira MAL, Várbíró G, Ekrem T (2019) DNA 705 barcode reference libraries for the monitoring of aquatic biota in Europe: Gap-analysis and 706 recommendations for future work. Science of The Total Environment 678: 499-524. 707 https://doi.org/10.1016/j.scitotenv.2019.04.247 
710 Figures

711
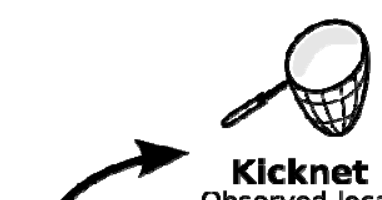
Observed local richness

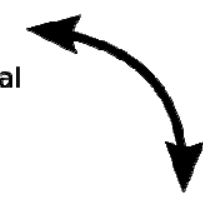

$Y=X \beta+\varepsilon$

Model

Estimated catchment

Observed catchment richness

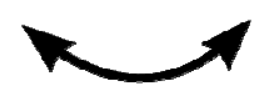

richness

1: A triad of methods (kicknet sampling, eDNA sampling, and statistical modelling) available to estimate macroinvertebrate diversity in river ecosystems. Each has its own specificities, particularly in terms of integrated spatial scale. Note that models always rely on underlying data used to train them, in this study those are independent kick-net samples. 
bioRxiv preprint doi: https://doi.org/10.1101/2022.01.03.474789; this version posted January 3, 2022. The copyright holder for this preprint (which was not certified by peer review) is the author/funder, who has granted bioRxiv a license to display the preprint in perpetuity. It is made available under aCC-BY 4.0 International license.

718

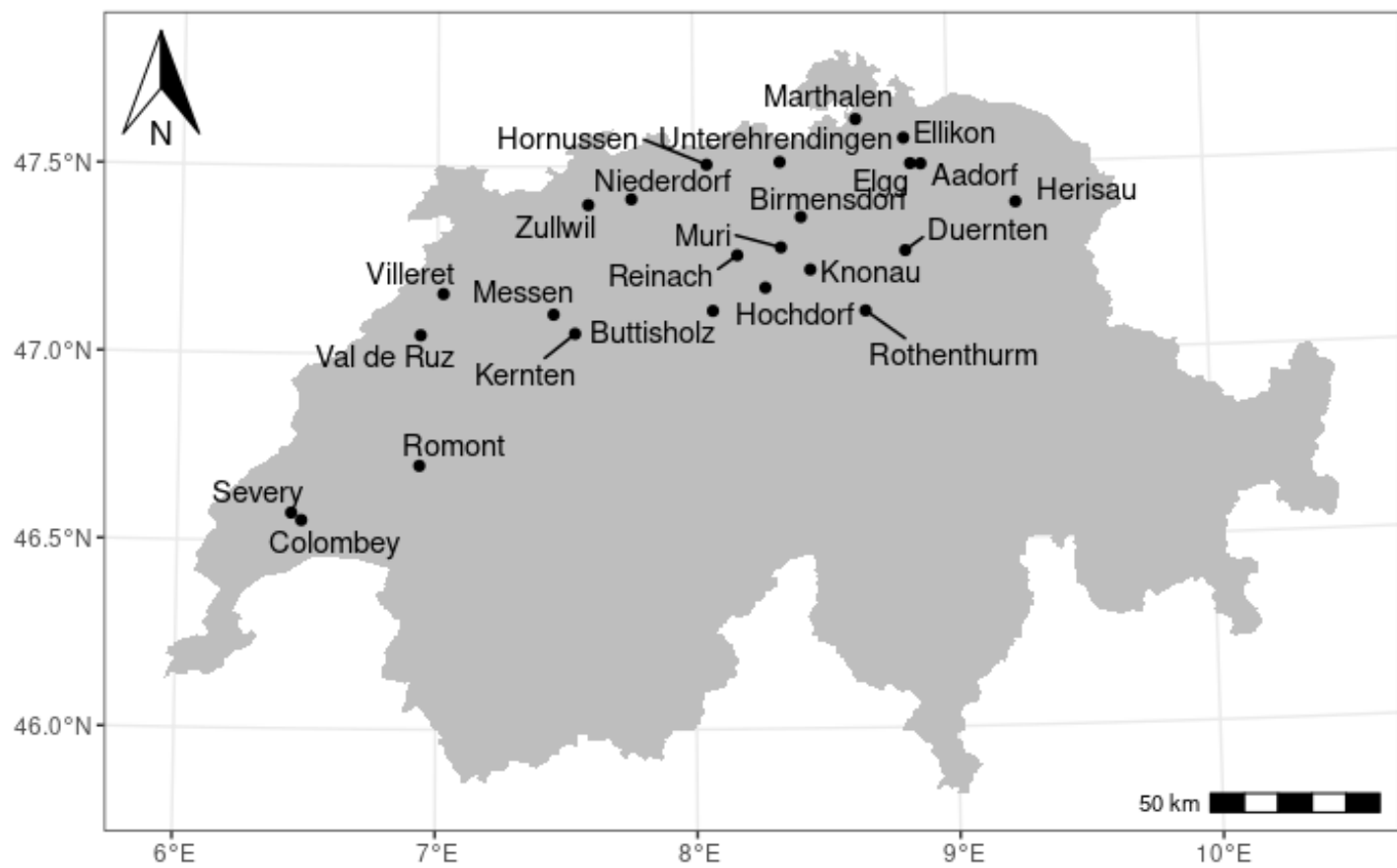

720 Figure 2: Map of Switzerland showing the 24 sampling locations. Locations are named after local municipalities. 
bioRxiv preprint doi: https://doi.org/10.1101/2022 01.03.474789; this version posted January 3,2022 . The copyright holder for this preprint (which was not certified by peer review) is the author/funder, who has granted bioRxiv a license to display the preprint in perpetuity. It is made available under aCC-BY 4.0 International license.

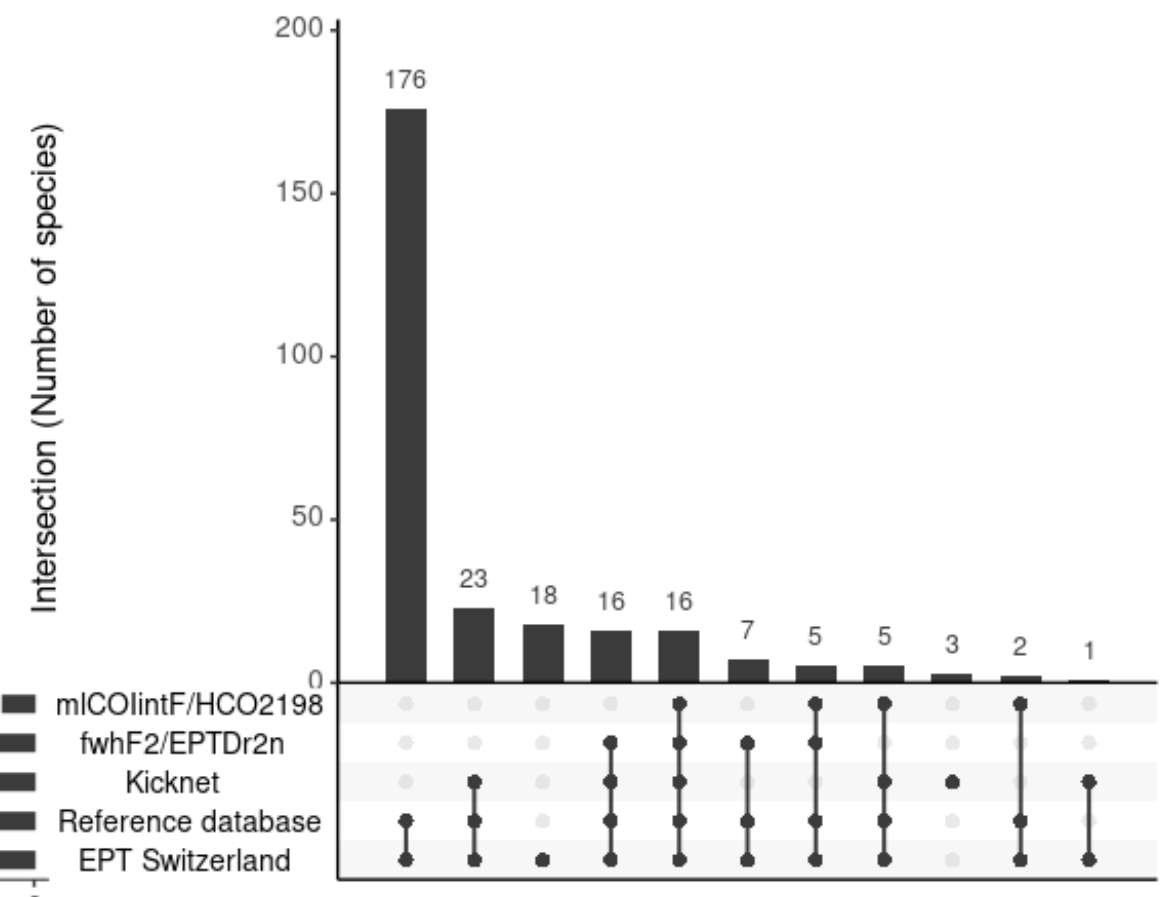
Number of species

Figure 3: Regional EPT species richness (diversity across all sampling locations) detected by eDNA (mlCOlintF/HCO2198 and fwhF2/EPTDr2n primers) and kicknet method in comparison to total EPT richness known from Switzerland and the subset of species included in the molecular reference database. Horizontal bars show the total number of species in each set. The vertical bars show the number of species in each intersection between sets. 
bioRxiv preprint doi: https://doi.org/10.1101/2022.01.03.474789; this version posted January 3, 2022. The copyright holder for this preprint (which was not certified by peer review) is the author/funder, who has granted bioRxiv a license to display the preprint in perpetuity. It is made available under aCC-BY 4.0 International license.

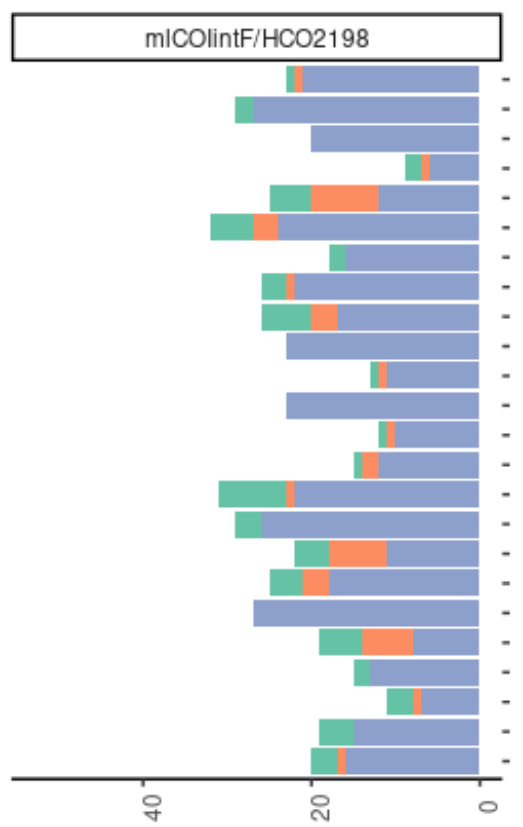

Number of taxa

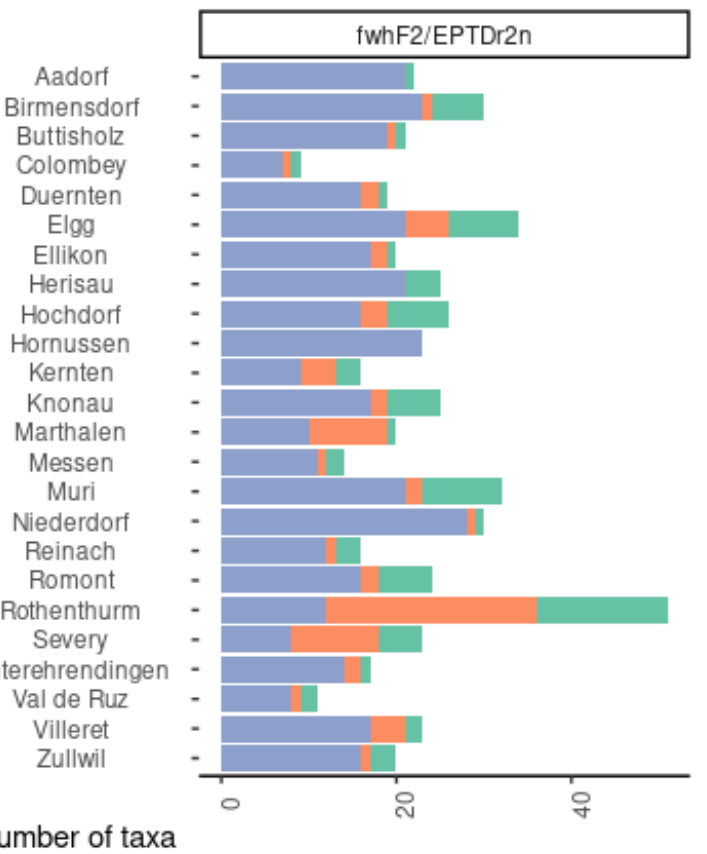

fraction

Both eDNA

Kicknet

Figure 4: Number of EPT taxa detected in each location by eDNA (mICOlintF/HCO2198 and fwhF2/EPTDr2n primers) and kicknet methods. The total number of taxa detected is divided in three fractions (in green the taxa detected by the two methods, in orange the taxa detected by eDNA only, and in blue the taxa detected by kicknet only, respectively). 
bioRxiv preprint doi: https://doi.org/10.1101/2022.01.03.474789; this version posted January 3, 2022. The copyright holder for this preprint (which was not certified by peer review) is the author/funder, who has granted bioRxiv a license to display the preprint in perpetuity. It is made available under aCC-BY 4.0 International license.

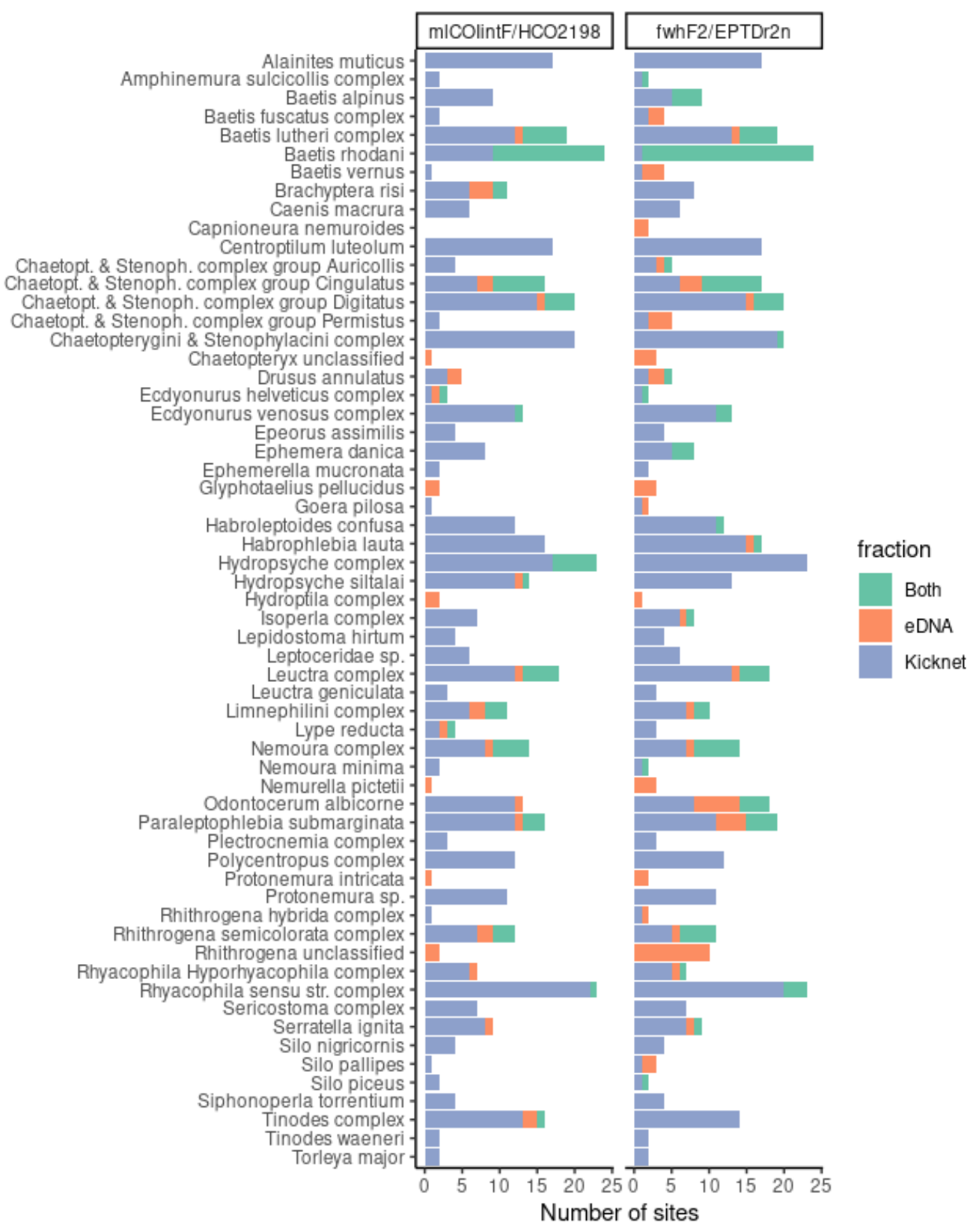

740 Figure 5: Number of streams where each EPT taxon was detected by eDNA

741 (mlCOlintF/HCO2198 and fwhF2/EPTDr2n primers) and kicknet methods. The total number

742 of locations is divided in three fractions (in green the locations where the taxon was detected

743 by the two methods, in orange the locations where the taxon was detected by eDNA only,

744 and in blue by kicknet only, respectively). For clarity, only the taxa detected more than once

745 (all streams and methods combined) are shown. 

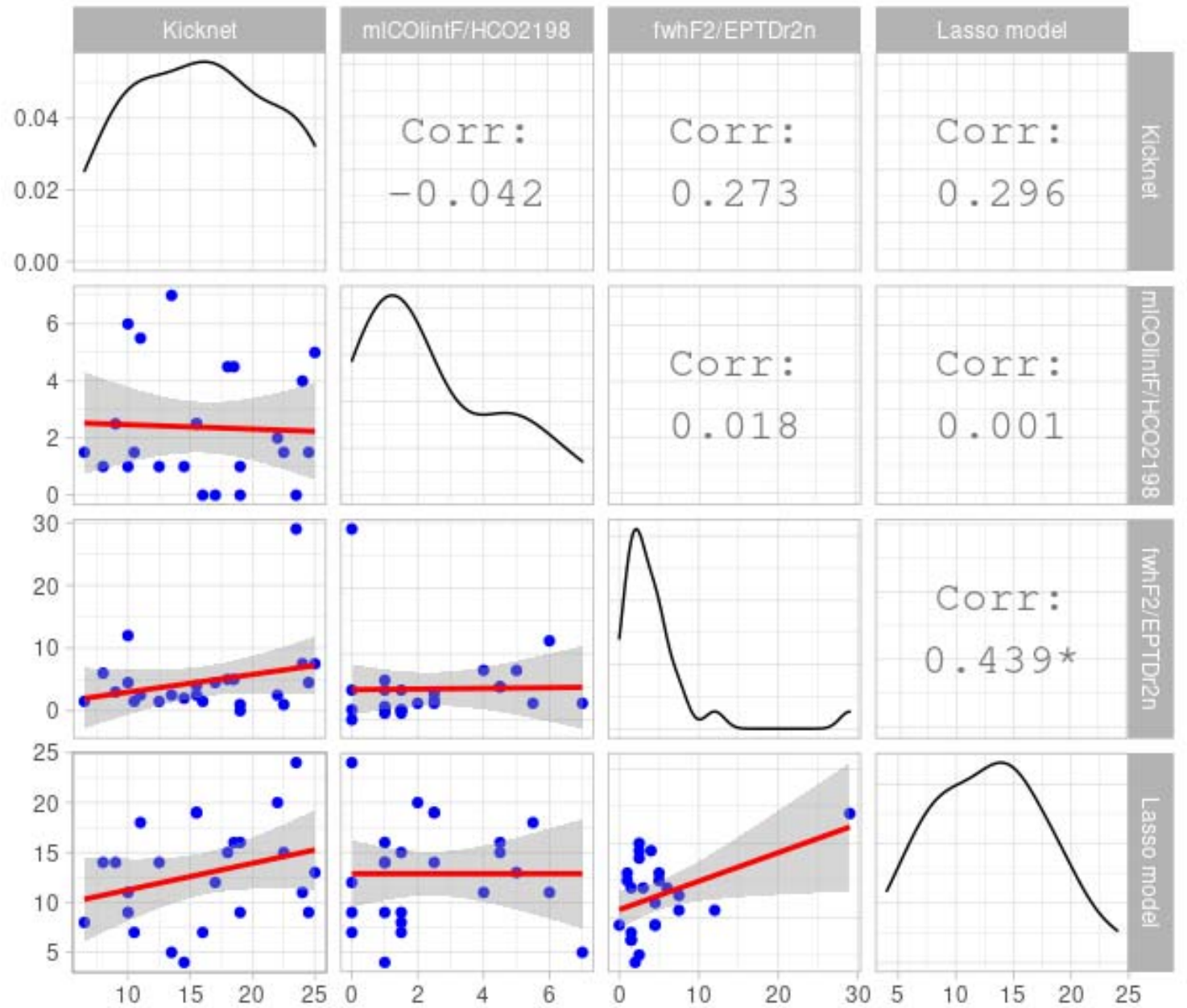

Figure 6: Relationships between the EPT richness estimates provided by the four investigated methods. The upper triangle provides the correlation values between each method (star indicates p-value < 0.05). Lower triangle shows the scatterplots with linear regressions (red lines). The diagonal shows the density estimate for each variable. 